\title{
Factors associated with acceptability of child adoption as a management option for infertility among women in a developing country
}

This article was published in the following Dove Press journal:

International Journal of Women's Health

30 July 2012

Number of times this article has been viewed

\author{
Adeniyi Abiodun \\ Adewunmi' \\ Elizabeth Arichi Etti' \\ Adetokunbo Olufela Tayo' \\ Kabiru Afolarin Rabiu' \\ Raheem Akinwunmi \\ Akindele ${ }^{2}$ \\ Tawakwalit Abimbola \\ Ottun' \\ Fatimat Motunrayo \\ Akinlusi' \\ 'Department of Obstetrics and \\ Gynaecology, Lagos State University \\ Teaching Hospital, Ikeja-Lagos, \\ ${ }^{2}$ Department of Physiology, Obafemi \\ Awolowo College of Health Sciences, \\ Olabisi Onabanjo University Teaching \\ Hospital, Sagamu-Ogun State, Nigeria
}

Correspondence: Adeniyi Abiodun Adewunmi

Institute of Fertility Medicine,

Department of Obstetrics and

Gynaecology, Lagos State University

Teaching Hospital, Ikeja-Lagos, Nigeria

Tel +23480 23077827

Email niyi_55@yahoo.com
Background: Adoption as a treatment option for infertility amongst those that cannot access and/or afford assisted reproduction is not well accepted in developing countries. This study sets out to determine the willingness of infertile women in developing countries to adopt a child and factors that influence women's attitude to adoption.

Methods: We conducted a questionnaire survey of consecutive infertile patients who attended the gynecological clinic of a regional teaching hospital over a 2-month period. Information on demographics, fertility history, and attitude to adoption was obtained, and the data were analyzed using SPSS version 16.0. Tests of statistical significance were used where appropriate at the 95\% confidence level.

Results: The majority of respondents were aware of child adoption, and the most common source of information was friends (47.8\%), followed by the media (39.7\%); $42.6 \%$ of respondents were willing to adopt if their infertility became intractable. The main reasons given by those unwilling to adopt were culture $(78.3 \%)$ and family constraints $(13.45 \%)$. On univariate analysis of factors associated with a favorable or unfavorable attitude to adoption, awareness of adoption $(P=0.002)$, duration of infertility $>5$ years $(P=0.015)$, no living child $(P=0.007)$, tertiary education $(P<0.001)$, pressure from parents $(P=0.041)$, household yearly income $\geq \$ 650$ $(P<0.001)$, and belief that treatment will bring about the desired results $(P<0.001)$ were significant, and all except awareness of adoption turned out to be significant on multiple logistic regression analysis.

Conclusion: There was a high level of awareness about child adoption among all respondents. However, the acceptability of adoption was significantly lower among poor women and those with limited education. Community advocacy and mobilization, especially through the media as well as via health care providers, will go a long way towards enlightening and enhancing the uptake of adoption among women in Nigeria.

Keywords: infertility, adoption, developing country, Nigeria

\section{Introduction}

Having children is an essential part of life for most people and in many cultures. Not having children on the other hand, is frequently considered a personal tragedy and a curse, impacting on the entire family and even the local community. There are also negative psychosocial consequences. ${ }^{1}$ In developing countries, where child-bearing is often highly valued, infertile couples are faced with problems ranging from overt ostracism or divorce to more subtle forms of social stigma leading to isolation and mental distress. ${ }^{2-4}$ Moreover, in most developing countries where there is no social security system, older people are completely dependent on their children. 
It is generally believed that more than 70 million couples suffer from infertility worldwide. ${ }^{5}$ Globally, the reported prevalence ranges from 5\% to 30\%. ${ }^{6}$ In Sub-Saharan Africa, the prevalence varies widely from $9 \%$ in the Gambia $^{7}$ and $11.8 \%$ in Ghana ${ }^{8}$ to $21.2 \%$ in northwestern Ethiopia ${ }^{9}$ and $20 \%-45 \%$ in Nigeria. ${ }^{10,11}$ In Asia and Latin America, the World Health Organization indicated values in the range of $8 \%-12 \%$ in $1991 .^{12}$

With figures as high as these, it is obvious that infertility has become a major public health problem in some developing countries, including Nigeria, with far reaching social and psychological consequences for affected individuals, their families, and the community. Therefore, many infertile couples will take considerable trouble to conceive and thus avoid the social and psychological problems associated with childlessness.

Bilateral tubal occlusion from infection is the most common underlying cause of infertility the world over. ${ }^{13}$ In recent times, there have been major advances in diagnosis and treatment, which have revolutionized the management of infertility. ${ }^{14}$ However, in developing countries, lack of access to health care facilities and the high cost of assisted reproductive technology remains a limiting factor in the management of many infertile couples. ${ }^{15}$ Despite recent strides in the management of infertility, $2 \%-7 \%$ of couples will remain childless at the end of their reproductive lives, ${ }^{16}$ and only about half of infertile couples achieve a live birth with fertility treatment. ${ }^{17}$ For many couples with intractable infertility, the situation is like bereavement and causes great emotional distress. ${ }^{18}$

In African societies such as ours, where a child-free lifestyle is not acceptable, ${ }^{19}$ many infertile couples are left with child adoption as their only option. There is no uniform child adoption law in Nigeria, and rules differ from state to state, despite the fact that the Child Rights Act was enacted by the National Assembly in 2003, and provides for child adoption. ${ }^{20}$ Studies carried out in Nigeria and other developing nations have shown that child adoption is not a well accepted option for infertile couples. ${ }^{21-27}$

Although studies have been done in Nigeria on the acceptability of child adoption as a solution to infertility, no such study has been done in Lagos, Nigeria's most populous metropolitan city with a population of 15.5 million people. ${ }^{28}$ Lagos is located in the south western region of Nigeria, but its population consists of a blend of almost all the ethnic groups, cultures, and religions in Nigeria. This is because it was the former capital of Nigeria and remains the economic and financial capital of the country. Against this background, the present study was conceptualized to determine the willingness of infertile women in the mixed population of Lagos to adopt, which would provide a good reflection of the prevailing attitude in Nigeria. The study also aimed to identify factors affecting attitudes to adoption that will help uncover tools that can be used to facilitate its general acceptance.

\section{Materials and methods Design and setting}

This was a descriptive cross-sectional study performed at the gynecological clinic of the Lagos State University Teaching Hospital, Ikeja, Lagos, in south-western Nigeria. The hospital is one of two tertiary referral hospitals in a city of 15.5 million people. ${ }^{28}$ Similar to other large teaching facilities in the region, its catchment includes not only urban women but also rural women who travel far from their villages to seek tertiary care. An average of about 60 patients $(20 \%$ of them new) attend the clinic Monday to Friday between 9 am and 4 pm, with 20-25 patients having infertility. Formal approval for the study was obtained from the research and ethics committee of the Lagos State University Teaching Hospital. Participation was voluntary, and only patients who gave their consent after the purpose of the study had been explained to them participated in the study.

\section{Study population and sample size determination}

The participants in this study comprised new and old patients with infertility who attended the gynecological clinic of the Lagos State University Teaching Hospital between December 1, 2009 and January 31, 2010. Studies have reported the prevalence of infertility in Nigeria to be $20 \%-45 \% .^{10,11}$ An average figure of $32 \%$ was used to calculate the sample size for this study, using the formula $n=Z^{2}$ $\mathrm{p}(1-\mathrm{p}) / \mathrm{e}^{2}$ to obtain a sample size of $334 .{ }^{29,30}$ We projected a sample size of 506, and the sample was a good representation of those who attended the infertility clinic.

\section{Data collection}

The instrument for data collection was a pretested, interviewer-administered, two-part, structured questionnaire. The purpose of the study was explained to the patients, and those who consented were interviewed by the authors. The names and addresses of participants were not included to maintain confidentiality and to elicit an honest response. The technique of face-to-face interview was used for data collection. The first part of the questionnaire consisted of a demographic 
and fertility history and the second part canvassed opinions about and willingness to adopt a baby.

\section{Data analysis}

The data were analyzed using SPSS version 16.0 (Statistical Package for Social Sciences Inc, Chicago, IL). Descriptive statistics (minimum, maximum, mean, and standard deviation) were applied for continuous variables and simple percentages for categorical variables. Tests of statistical significance were used where appropriate, and $P<0.05$ was considered to be statistically significant ( $95 \%$ confidence level). Univariate and multiple logistic regression analysis was used for some of the variables to identify factors which affect respondents' attitudes to child adoption.

\section{Results}

Five hundred and six consecutive infertile women seen during the study period completed the questionnaire. However, only 500 questionnaires were able to be analyzed. The sociodemographic characteristics of the respondents are shown in Table 1. The women were aged $16-51$ years, with a mean age of $34.11 \pm 5.32$ years. They were of mixed ethnicity, with $64.6 \%$ being Yoruba, $18.0 \%$ being Igbo, and the remainder belonging to the Hausa or other Nigerian tribes. Twenty-four percent of respondents were Muslims, while $75.6 \%$ were Christians, predominantly Pentecostals. Only $1.8 \%$ of the respondents had no formal education, while $12.4 \%, 35.0 \%$, and $50.8 \%$ had primary, secondary, and tertiary education, respectively. Most respondents $(81.1 \%)$ had a yearly household income of more than $\$ 650$. Almost all respondents (98.0\%) were married, and the duration of their relationships is shown in Table 1.

The infertility history of the respondents is shown in Table 2. One hundred and nine women $(22.0 \%)$ had primary infertility, and $386(78 \%)$ had secondary infertility. The duration of infertility ranged from 1 to 27 years, and the mean duration of infertility was $5.31 \pm 4.17$ years. Three hundred and fifty-four respondents $(70.9 \%)$ had no living children, while 145 (29.1\%) had one or more living children. One hundred and eighty-one (36.6\%) respondents had not been fully investigated. Of those who had been fully investigated, $43.9 \%, 21.0 \%, 20.1 \%$, and $15.0 \%$ had female factor, male factor, combined male and female factor, or unknown cause of infertility, respectively. Over half of the respondents $(55.8 \%)$ had received orthodox treatment, and six (1.2\%) had used an assisted reproductive technique unsuccessfully. One hundred and eighty-four respondents $(36.8 \%)$ had never received any form of treatment for
Table I Sociodemographic characteristics of respondents

\begin{tabular}{|c|c|c|c|}
\hline Variables & \multicolumn{2}{|l|}{$\mathbf{n}$} & Percentage \\
\hline \multicolumn{4}{|l|}{ Tribe } \\
\hline Yoruba & \multicolumn{2}{|l|}{320} & 64.6 \\
\hline lbo & \multicolumn{2}{|l|}{89} & 18.0 \\
\hline Hausa & \multicolumn{2}{|l|}{3} & 0.6 \\
\hline Others & \multicolumn{2}{|l|}{83} & 16.8 \\
\hline \multicolumn{4}{|l|}{ Religion } \\
\hline Islam & \multicolumn{2}{|l|}{122} & 24.4 \\
\hline Christianity & \multicolumn{2}{|l|}{377} & 75.6 \\
\hline Catholic & \multicolumn{2}{|l|}{32} & 6.4 \\
\hline Pentecostal & \multicolumn{2}{|l|}{312} & 62.5 \\
\hline White Garment & \multicolumn{2}{|l|}{14} & 2.8 \\
\hline Jehovah's Witness & \multicolumn{2}{|l|}{5} & 1.0 \\
\hline Orthodox & \multicolumn{2}{|l|}{14} & 2.8 \\
\hline Traditional religion & \multicolumn{2}{|l|}{ None } & - \\
\hline \multicolumn{4}{|l|}{ Educational level } \\
\hline None & \multicolumn{2}{|l|}{9} & 1.8 \\
\hline Primary & \multicolumn{2}{|l|}{62} & 12.4 \\
\hline Secondary & \multicolumn{2}{|l|}{175} & 35.0 \\
\hline Tertiary & \multicolumn{2}{|c|}{254} & 50.8 \\
\hline \multicolumn{4}{|c|}{ Household yearly income (US Dollars) } \\
\hline$<\$ 300$ & \multicolumn{2}{|c|}{19} & 3.8 \\
\hline$\$ 300-\$ 650$ & \multicolumn{2}{|l|}{75} & I5.| \\
\hline$>\$ 650$ & \multicolumn{2}{|l|}{402} & 81.1 \\
\hline \multicolumn{4}{|l|}{ Relationship status } \\
\hline Married & \multicolumn{2}{|l|}{487} & 98.0 \\
\hline Cohabiting & \multicolumn{2}{|l|}{4} & 0.8 \\
\hline Single & \multicolumn{2}{|l|}{6} & 1.2 \\
\hline \multicolumn{4}{|c|}{ Duration of relationship (years) } \\
\hline $\mathrm{I}-5$ & 274 & & 55.1 \\
\hline $6-10$ & 140 & & 28.2 \\
\hline $11-15$ & 44 & & 8.9 \\
\hline$>15$ & 39 & & 7.8 \\
\hline & Mean & SD & Range \\
\hline Age (years) & 34.11 & 5.32 & $|6-5|$ \\
\hline Duration of infertility (years) & 5.31 & 4.17 & $\mathrm{I}-27$ \\
\hline
\end{tabular}

Abbreviations: SD, standard deviation; \$, US dollar.

their infertility. Three hundred and ten respondents (62.0\%) had been subjected to pressure from their parents, either the husband's, wife's, or both parents, while the rest experienced no parental pressure regarding infertility.

Table 3 summarizes the knowledge and attitudes as well as acceptability of child adoption amongst the respondents. Almost all respondents (97.2\%) were aware of child adoption, and the most common sources of knowledge were friends (47.8\%) and the media (39.7\%), while health care providers were the source of knowledge in $4.4 \%$ of respondents. Two hundred and thirty-six (47.5\%) respondents believed that treatment would have the desired outcome. Most based their belief on faith $(79.9 \%)$, but $20.3 \%$ based their belief on the success rates of the treatment options. In this study, $235(47.0 \%)$ respondents thought that adoption should be encouraged and $211(42.6 \%)$ said 
Table 2 Infertility history of respondents

\begin{tabular}{lll}
\hline Variables & No & Percentage (\%) \\
\hline Type of infertility & 109 & 22.0 \\
Primary & 386 & 78.0 \\
Secondary & & \\
Duration of infertility (years) & 315 & 63.0 \\
I-5 & 141 & 28.2 \\
$6-10$ & 28 & 5.6 \\
II-I5 & 16 & 3.2 \\
I5 & & \\
Living children (n) & 354 & 70.9 \\
None & 145 & 29.1 \\
$\geq$ I & 138 & 43.9 \\
Cause of infertility (in 314 fully investigated respondents) \\
Female factor & 66 & 21.0 \\
Male factor & 63 & 20.1 \\
Combined male and female factor & 47 & 15.0 \\
Unknown & & \\
Previous treatment & 184 & 36.8 \\
None & 219 & 43.8 \\
Orthodox & 6 & 1.2 \\
Assisted reproductive technique & 37 & 7.4 \\
Traditional medicine & 54 & 10.8 \\
Orthodox and traditional medicine & & \\
Pressure from parents & 310 & 62.0 \\
Yes & 190 & 38.0 \\
No & & \\
\hline
\end{tabular}

that they were willing to adopt if their infertility became intractable. The reasons given by the $57.4 \%$ of respondents who were unwilling to adopt included religion (8.3\%), cultural concerns $(78.3 \%)$, and lack of family support (13.4\%). Of those who were willing to adopt, 129 (59.2\%) did not mind the gender of the child, while $46(21.1 \%)$ and $43(19.7 \%)$ preferred a male or female child, respectively. Most respondents were willing to raise a child from a member of their family (95.2\%), and even from someone they knew who was not a member of their family (93.4\%), without formally adopting the child.

A univariate analysis of factors associated with a favorable attitude to child adoption is shown in Table 4. Of the 13 variables tested, seven were found to be statistically significant and included awareness of adoption $(P=0.002)$, duration of infertility of more than 5 years $(P=0.015)$, no living child $(P=0.007)$, tertiary education $(P<0.001)$, pressure from parents $(P=0.041)$, yearly household income $\geq \$ 650$ $(P<0.001)$, and belief that treatment would have the desired outcome $(P<0.001)$. In Table 5 , the factors tested in Table 4 were subjected to a multivariate analysis, except for awareness of adoption. All factors found to be significant in the univariate analysis were still found to be significant on multiple logistic regression analysis.

\section{Discussion}

This study showed that almost all respondents were aware of child adoption, which is higher than the $86.4 \%$ quoted by a similar study in Nigeria. ${ }^{22}$ Studies carried out in Nigeria and other developing nations have shown that child adoption is not a well accepted option for management of infertility. ${ }^{21,27}$

The most common sources of knowledge were friends and the media. Health care providers, on the other hand, were sources of information on child adoption for few respondents. This reflects the reluctance of health care providers to counsel patients on the need to consider adoption when necessary. This may be due to the prevailing attitude of the patients themselves that their infertility is curable. In fact, this was typified by the attitude of respondents while being interviewed. Despite the fact that they were informed about the nature and purpose of the study, and verbal informed consent was obtained prior to administration of the questionnaires, most responded with an initial vehement "God forbid" when asked what they would do if their infertility became intractable, before they thought about the question. Interestingly, even after reacting in this manner, many respondents were still willing to adopt if necessary. This demonstrates the place and importance of counseling, which health care providers must offer to infertile clients.

In this study, almost half of the respondents thought that child adoption should be encouraged, and the majority were willing to adopt if their infertility became intractable. This is higher than the $30.7 \%$ and $34.1 \%$ obtained in two different studies done in Nigeria in $2002,{ }^{22,23}$ but similar to more recent research in Ibadan ${ }^{24}$ and Pakistan, ${ }^{27}$ while a study in the US showed a much higher acceptability rate of $79 \% .{ }^{31}$ Although child adoption acceptability rates are much higher in developed than in developing nations, increasing acceptability of child adoption in Nigeria over the years is demonstrated by this study and is most likely due to a growing awareness and knowledge about adoption enhanced by media publicity.

People in this part of the world are known to be very religious. This is seen in the fact that almost half of the respondents believed that treatment of their infertility will have the desired outcome, and the majority based their belief on faith rather than on the actual success rate of treatment. This is important because the belief that treatment always brought about the desired outcome was found to be significantly associated with an unfavorable attitude to child adoption. This means that those who thought that treatment would have the desired outcome because of their faith were less willing to adopt. The general belief is that infertility is temporary. 
Table 3 Knowledge of and attitude towards child adoption by respondents

\begin{tabular}{|c|c|c|c|}
\hline Question & Answer & $\mathbf{n}$ & Percentage \\
\hline \multirow[t]{2}{*}{ Aware of child adoption? } & Yes & 486 & 97.2 \\
\hline & No & 14 & 2.8 \\
\hline \multirow[t]{6}{*}{ Where did you first hear about adoption? } & Family & 25 & 5.2 \\
\hline & Friends & 229 & 47.8 \\
\hline & Health care providers & 21 & 4.4 \\
\hline & Media & 190 & 39.7 \\
\hline & Religious institution & 9 & 1.9 \\
\hline & School & 5 & 1.0 \\
\hline \multirow[t]{3}{*}{ Should adoption be encouraged? } & Yes & 235 & 47.0 \\
\hline & No & 167 & 33.4 \\
\hline & Do not know & 95 & 19.0 \\
\hline \multirow[t]{3}{*}{ Do you think treatment will always give a desired result? } & Yes & 236 & 47.5 \\
\hline & No & 142 & 28.6 \\
\hline & Do not know & 119 & 23.9 \\
\hline \multirow{3}{*}{$\begin{array}{l}\text { If your answer to the question above is yes, what is } \\
\text { your belief based on? }\end{array}$} & Success rate of & 48 & 20.3 \\
\hline & treatment options & & \\
\hline & Faith & 188 & 79.7 \\
\hline \multirow[t]{2}{*}{ What would you do if all treatment fails? } & Adoption & 211 & 42.6 \\
\hline & Nothing & 284 & 57.4 \\
\hline \multirow[t]{3}{*}{ Why do you not want adoption? } & Religion & 23 & 8.3 \\
\hline & Cultural & 216 & 78.3 \\
\hline & Family & 37 & 13.4 \\
\hline \multirow[t]{3}{*}{ If you were to adopt what sex would you prefer? } & Male & 46 & 21.1 \\
\hline & Female & 43 & 19.7 \\
\hline & Either & 129 & 59.2 \\
\hline Would you accept raising a child from a member & Yes & 476 & 95.2 \\
\hline of your family? & No & 24 & 4.8 \\
\hline Would you accept raising a child from someone & Yes & 467 & 93.4 \\
\hline you know who is not a member of your family? & No & 33 & 6.6 \\
\hline
\end{tabular}

This encourages couples to wait patiently for several years (as long as 15-20 years in some instances), thereby making them less likely to accept adoption as a solution. ${ }^{32}$

The most common reasons given for unwillingness to adopt were cultural, eg, the background of the child is unknown and the child may not be kin and so cannot have inheritance or genealogical rights. Other concerns were fear of abnormal behavior in the child or diseases inherited from biological parents which may be socially unacceptable (eg, psychiatric illness or epilepsy). There was also the fear that the child may abandon them once he/she learned that he/she was adopted, considering that the adoption would probably be common knowledge and someone outside the home may inform the child. For many respondents, the prospect of adoption was psychologically unacceptable and they felt they could not love the child as their own.

Family reasons were cited by a few respondents who were unwilling to adopt. This was usually seen in respondents who could be positively inclined to adoption but perceived that they would lack their husband's, parents', or in-laws' support, to the point of causing marital disharmony. These cultural and family reasons given for not accepting child adoption are similar to those seen in previous studies in developing countries. ${ }^{22,24}$

Very few respondents cited religious reasons for considering adoption to be unacceptable. However, the reasons offered are worthy of note. Some Muslim respondents stated that adoption was prohibited by their religion. In fact, in Egypt, under Muslim law, adoption is illegal. ${ }^{33}$ Some Christian respondents, on the other hand, were unwilling to adopt because they felt that adopting a child translates into a lack of faith in God who will therefore not answer their prayers.

Interestingly, this study showed that there were more respondents willing to raise a child from a relative or an unrelated friend or acquaintance than those willing to adopt a child. Child fostering is widely practiced in traditional African societies, although is not yet institutionalized in Nigeria. ${ }^{25,32}$ There is a proverb in the Yoruba culture of southwest Nigeria that says "only one person gives birth to a child, but many people take part in rearing him or her". ${ }^{25}$

Factors such as no living child, awareness of adoption, and infertility for more than 5 years were found to be 
Table 4 Univariate analysis of factors associated with a favorable attitude to child adoption

\begin{tabular}{|c|c|c|c|c|c|}
\hline \multirow[t]{3}{*}{ Factor } & \multicolumn{4}{|c|}{ Attitude to adoption } & \multirow[t]{3}{*}{$P$ value } \\
\hline & \multicolumn{2}{|c|}{$\begin{array}{l}\text { Favorable } \\
(n=21 I) \\
\end{array}$} & \multicolumn{2}{|c|}{$\begin{array}{l}\text { Unfavorable } \\
(n=284)\end{array}$} & \\
\hline & $\mathbf{n}$ & $\%$ & $\mathbf{n}$ & $\%$ & \\
\hline Duration of infertility ( $>5$ years) & 65 & 35.5 & 118 & 64.5 & 0.015 \\
\hline Age of female partner ( $\geq 35$ years) & 90 & 40.5 & 132 & 59.5 & $0.412 * *$ \\
\hline $\begin{array}{l}\text { Previous orthodox or assisted } \\
\text { conception treatment }\end{array}$ & 122 & 43.9 & 156 & 56.1 & $0.583^{* *}$ \\
\hline Have living children & 47 & 33.1 & 95 & 66.9 & 0.007 \\
\hline Literacy level up to tertiary & 137 & 54.6 & 114 & 45.4 & $<0.001$ \\
\hline Pressure from parents & 119 & 39 & 186 & 61 & 0.041 \\
\hline Household yearly income $\geq \$ 650$ & 187 & 46.6 & 214 & 53.4 & $<0.001$ \\
\hline Awareness of adoption & 211 & 43.7 & 272 & 56.3 & 0.002 \\
\hline Female factor & 85 & 42.1 & 117 & 57.9 & $0.854 * *$ \\
\hline Male factor & 29 & 45.3 & 35 & 54.7 & $0.684 * *$ \\
\hline Combined factor & 23 & 36.5 & 40 & 63.5 & $0.341^{* *}$ \\
\hline $\begin{array}{l}\text { Patients' belief that treatment } \\
\text { will always give desired result }\end{array}$ & 92 & 39.3 & 142 & 60.7 & $<0.001$ \\
\hline $\begin{array}{l}\text { Patients' belief in the success rate } \\
\text { of treatment option }\end{array}$ & 19 & 40.4 & 28 & 59.6 & $0.869 * *$ \\
\hline
\end{tabular}

Note: $* *$ Not statistically significant at $95 \%$ confidence level.

significantly associated with a positive attitude towards child adoption in this study, and were similar to the findings of a previous study in Nigeria. ${ }^{22}$ A study in the US also demonstrated that duration of infertility of more than 5 years was significantly associated with a positive attitude towards child adoption. ${ }^{34}$ Other factors found to be significant in this study include pressure from parents, having tertiary education, a yearly household income of $\geq \$ 645$, and the belief that treatment will always have the desired

Table 5 Multivariate analysis of factors associated with a favorable attitude to child adoption

\begin{tabular}{llll}
\hline Factor & OR & Cl & P value \\
\hline Duration of infertility ( $>5$ years) & 0.626 & $0.43-0.91$ & 0.015 \\
Age of female partner ( $\geq 35$ years) & 0.856 & $0.60-1.23$ & $0.398^{* *}$ \\
$\begin{array}{l}\text { Previous orthodox or assisted } \\
\text { conception treatment }\end{array}$ & 1.125 & $0.79-1.61$ & $0.520^{* *}$ \\
No living children & & & \\
Literacy level up to tertiary & 1.763 & $1.17-2.65$ & 0.006 \\
Pressure from parents & 0.362 & $0.25-0.52$ & 0.000 \\
Household yearly income $\geq$ US $\$ 650$ & 0.682 & $0.47-0.98$ & 0.040 \\
Female factor & 0.381 & $0.23-0.64$ & 0.000 \\
Male factor & 0.963 & $0.67-1.38$ & $0.838^{* *}$ \\
Combined factor & 1.143 & $0.67-1.94$ & $0.619^{* *}$ \\
Patients' belief that treatment & 0.752 & $0.44-1.30$ & $0.308^{* *}$ \\
will always give desired result & 2.084 & $1.34-3.58$ & 0.001 \\
Patients' belief in the success & & & \\
rate of treatment option & 1.060 & $0.55-2.04$ & $0.862^{* *}$ \\
\hline Notes: $O R$ not sign & & & \\
\hline
\end{tabular}

Notes: **OR not significant at $95 \% \mathrm{Cl}$. OR could not be computed for "awareness of adoption" because all patients who were not aware of adoption would not take adoption as an option for infertility.

Abbreviations: $\mathrm{Cl}$, confidence interval; OR, odds ratio. outcome. The explanation for these significant factors is not far-fetched. For instance, a woman who has one or more living children, may not see the reason to adopt another one as a solution to her problem. In fact, many respondents with one or more children alive were unwilling to adopt and cited this very reason. Similarly, knowing about adoption is likely to remove misconceptions and make a couple more willing to adopt a child. A person whose duration of infertility is more than 5 years will more likely experience personal pressure and pressure from parents, which may make that person more determined to find a solution to the problem, and so embrace adoption. Having tertiary education suggests that a person is enlightened and probably better informed about such issues. Having enlightenment and information about adoption has already been shown to affect attitudes to adoption favorably. Thus, a person who has tertiary education is more likely to have a correct understanding and a more favorable attitude towards adoption. It is also likely that those who earn $\geq \$ 650$ per year would feel more capable of going through the rigorous bureaucracy involved in child adoption, which is often financially demanding. The social welfare department, the agency of government charged with the responsibility of child adoption, usually inspects the homes and living conditions of prospective adoptive parents, to assess their capability to cater adequately for adoptees. This may be discouraging for those who earn less and have poorer living conditions, thereby making them less willing to adopt. 


\section{Conclusion}

There was a surprisingly high level of awareness about child adoption among the respondents in this study. However, the acceptability of adoption was significantly lower among poor women and those with limited education. Community advocacy and mobilization, especially through the media, as well as health care providers playing their role in counseling, will go a long way towards enlightenment and enhancement of the uptake of child adoption by women in developing countries.

\section{Acknowledgments}

The authors acknowledge the contribution of the medical records department staff from Lagos State University Teaching Hospital to this study.

\section{Disclosure}

The authors declare no conflicts of interest in this work.

\section{References}

1. Dyer SI. The value of children in African countries, insight from studies in infertility. J Psychosom Obstet Gynaecol. 2007;28:69-77.

2. Rutstein SO, Shah IH. Infecundity, infertility and childlessness in developing countries. DHS Comparative Reports, No 9. Calverton, MD: ORC Macro and the World Health Organization; 2004. Available from: http://www.who.int/reproductivehealth/topics/infertility/DHS-CR9.pdf. Accessed June 21, 2012.

3. Aina OF. An overview of the sociocultural and psychiatric aspects of women's reproductive health in West Africa. Niger Postgrad Med J. 2007; 14:231-237.

4. Ameh N, Kene TS, Onuh SO, Okohue JE, Umeorah DU, Anozie OB. Burden of domestic violence amongst infertile women attending infertility clinics in Nigeria. Niger J Med. 2007;16:375-377.

5. Boivin J, Bunting L, Collins JA, Nygren KG. International estimates of infertility prevalence and treatment-seeking: potential need and demand for infertility medical care. Hum Reprod. 2007;22:1506-1512.

6. Inyang-Etoh PC, Ogban GI, Inyang-Etoh EC, Useh MF, Etuk SJ. Prevalence of Chlamydia trachomatis infection among women attending infertility clinics in Calabar, Nigeria. Nigerian Journal of Health and Biomedical Sciences. 2009;8:16-20.

7. Sundby JA, Mboge R, Sonko S. Infertility in the Gambia: frequency and health care seeking. Soc Sci Med. 1998;46:891-899.

8. Geehoed DW, Nayembi D, Asare K, Schagen Van Leenwen JH, Rossmalen J. Infertility in rural Ghana. Int $J$ Gynaecol Obstet. 2002;79:137-142.

9. Haile A. Fertility conditions in Gordon, north western Ethiopia; an appraisal of current status. Stud Fam Plann. 1999;340:177-183.

10. Okonofua EF. Female and male infertility in Nigeria; studies on epidemiology of infertility in Nigeria with special reference to the role of genital tract infections and sexual and reproductive risk factors. Dissertation, Stockholm, Sweden: Karolinska Institutet; 2005.

11. Larsen V. Primary and secondary infertility in Sub-Sahara. Int $J$ Epidemiol. 2000;29:285-291.

12. World Health Organization. Infertility: a tabulation of available data on prevalence of primary and secondary infertility. Geneva, Switzerland: World Health Organization; 1999.

13. Nachigall RD. International disparities in access to infertility services. Fertil Steril. 2006;85:871-875.
14. Society for Assisted Reproductive Technologies. Assisted reproductive technologies in the United States: 2000 results. Fertil Steril. 2004;81:207-220.

15. Okonofua FE. New reproductive technologies and infertility treatment in Africa. Afr J Reprod Health. 2003;7:7-11.

16. Kalantar SM, Kazemi MJ, Sheikhha MH, Afflatoonian A, Kafilzadeh F. Detection of Chlamydia trachomatis infection in female partners of infertility couples. Iranian Journal of Fertility and Sterility. 2007;2:79-84.

17. Leridon $H$. Can assisted reproduction technology compensate for the natural decline in fertility with age? A model assessment. Hum Reprod. 2004;19:1548-1553.

18. Van den Akker OB. Coping, quality of life and psychological symptoms in three groups of sub-fertile women. Patient Educ Couns. 2005;57:183-189.

19. Orji EO, Kuti O, Fasubaa OB. Impact of infertility on marital life in Nigeria. Int J Gynaecol Obstet. 2002;79:61-62.

20. Chukwu LOC. Adoption of children in Nigeria under the Child's Rights Act 2003. Available from: http://www.law2.byu.edu/isfl/saltlake confernce/papers/isflpdfs/Chukwu.pdf. Accessed June 21, 2012.

21. Araoye MO. Epidemiology of infertility: social problems of the infertile couples. West Afr J Med. 2003;22:190-196.

22. Ezugwu FO, Obi SN, Onah HE. The knowledge, attitude and practice of child adoption among infertile Nigerian women. J Obstet Gynaecol. 2002;22:211-216.

23. Onah HE, Ogbuokiri CM. The knowledge and attitude of fertile and infertile Nigerians regarding adoption. Int $J$ Gynaecol Obstet. 2002;79:279-280.

24. Oladokun A, Arulogun OS, Oladokun R, et al. Child adoption as treatment option for infertility in Nigeria. Available from: http://iussp2009. princeton.edu/download.aspx?submissionId=92704. Accessed June 21, 2012.

25. Oladokun A, Arulogun OS, Oladokun R, et al. Acceptability of child adoption as a management option for infertility in Nigeria: evidence from focus group discusssions. Afr J Reprod Health. 2009;13:79-91.

26. Bharadwaj A. Why adoption is not an option in India: the visibility of infertility, the secrecy of donor insemination, and other cultural complexities. Soc Sci Med. 2003;56:1867-1880.

27. Ali TS, Sami N. Adoption practices among couples with secondary infertility in Karachi: a triangulation study design. J Pak Med Assoc. 2007;57:55-59.

28. Nigeriamuse.com. Errors, miscalculations, omissions in Lagos census figures. Available from: http://www.nigeriamuse. com/200702072340372 g/important_documts/lagos_census_affairs. Accessed April 15, 2010.

29. Cohen J. Statistical Power Analysis for Behavioral Sciences. 2nd ed. Hillsdale, NJ: Lawrence Erlbaum and Associates; 1988.

30. Lemeshow S, Hosmer D, Klar J, Lwanga S. Sample size for samples surveys. In: Lemeshow S, Hosmer D, Klar J, Lwanga S, editors. Adequacy of Sample Size in Health Studies. Chichester, UK: John Wiley and Sons; 1990.

31. National Centre for Health Statistics, Centers for Disease Control. Adoption experiences of women and men and demand for children to adopt by women 18-44 years of age in the United States; 2002. Vital Health Stat. 2008;27:1-36.

32. Koster-Oyekan W. Infertility among Yoruba women: perception on causes, treatment and consequences. AfrJ Reprod Health. 1999;3:13-26.

33. Inhorn MC. "He won't be my son": Middle Eastern Muslim men's discourses of adoption and gamete donation. Med Anthropol $Q$. 2006;20:94-120.

34. Chandra A, Abma J, Maza P, Bachrach C. Adoption, adoption seeking and relinquishment for adoption in the United States. Adv Data. 1999;306:1-16. 
International Journal of Women's Health

Dovepress

\section{Publish your work in this journal}

The International Journal of Women's Health is an international, peerreviewed open-access journal publishing original research, reports, reviews and commentaries on all aspects of women's healthcare including gynecology, obstetrics, and breast cancer. Subject areas include: Chronic conditions (migraine headaches, arthritis, osteoporosis);

Endocrine and autoimmune syndromes; Sexual and reproductive health; Psychological and psychosocial conditions. The manuscript management system is completely online and includes a very quick and fair peer-review system. Visit http://www.dovepress.com/ testimonials.php to read real quotes from published authors.

Submit your manuscript here: http://www.dovepress.com/international-journal-of-womens-health-journal 